Check for updates

Cite this: RSC Adv., 2019, 9, 27646

\title{
Effect of vacancies on the structural and electronic properties of $\mathrm{Ti}_{2} \mathrm{CO}_{2}$
}

\author{
Li Xiao-Hong, (D)* Su Xiang-Ying and Zhang Rui-Zhou
}

$\mathrm{Ti}_{2} \mathrm{CO}_{2} \mathrm{MXene}$ is widely considered as a potential candidate material for sensors and optical devices. In this paper, first-principles calculations are performed to investigate the structural and electronic properties of pristine and vacancy defect $\mathrm{Ti}_{2} \mathrm{CO}_{2}$ monolayer. The results indicate that $\mathrm{C}$-vacancy is energetically more favorable than Ti-vacancy and $\mathrm{O}$-vacancy because of the smaller formation energy of $\mathrm{C}$ vacancy. The introduction of vacancy defects results in the transition from semiconductor to metal, and improves the electronic conductivities of $\mathrm{Ti}_{2} \mathrm{CO}_{2}$ monolayer. The introduction of $\mathrm{C}$ and $\mathrm{O}$ vacancies causes the $\mathrm{Ti}$ $\mathrm{d}$ state to split into several peaks in the energy range of 0 to $2 \mathrm{eV}$, while the introduction of Ti vacancy makes the Ti-d state weaker and the $\mathrm{C}-\mathrm{p}$ state stronger. Furthermore, the work function can be effectively engineered by vacancy defects.

Received 11th June 2019

Accepted 28th August 2019

DOI: $10.1039 / c 9 r a 04393 d$

rsc.li/rsc-advances engineered by defects. For the low-dimensional materials, defects have a much stronger impact, when compared to their bulk counterparts. And defect engineering has attracted extensive attention ${ }^{17}$ and is often used to modify the electronic structures of many layered structures. ${ }^{18}$ Zhang et al. ${ }^{19}$ theoretically investigated the carbon-vacancy ordering in $\mathrm{Nb}_{4} \mathrm{AlC}_{3-x}$, and reported the importance roles of carbon vacancies in the structure stability and order-disorder phase transformation. Carbon vacancies also have important influences on the superconducting properties of materials. ${ }^{20-22}$

Vacancies are universally present in the MAX phases. ${ }^{23,24}$ So it is believed that MXenes inherit their hosts' defect. $\mathrm{Ti}_{2} \mathrm{CO}_{2}$ is the thinnest O-functionalized Ti-based MXene, and has many promising applications, such as catalyst, optical devices, and gas sensor. ${ }^{25-27}$ Wang et al. ${ }^{28}$ investigated the stabilities and electronic properties of vacancy-doped $\mathrm{Ti}_{2} \mathrm{CO}_{2}$. Their results indicated that the formation energies of $\mathrm{C}$-vacancy are relatively small. Hu et $a .^{29}$ reported the influence of C-vacancy on the structural stability, electronic properties of a $2 \times 2 \times 1 \mathrm{Ti}_{2} \mathrm{CT}_{2}$ ( $\mathrm{T}=\mathrm{O}, \mathrm{F}$, and $\mathrm{OH}$ ) supercell. They thought that C-vacancy in MXene is much easier to form when compared with graphene and other two-dimensional material. Bandyopadhyay et al. ${ }^{30}$ investigated the structural and magnetoelectronic behavior of a $4 \times 4 \times 1 \mathrm{Ti}_{2} \mathrm{CO}_{2}$ supercell with single vacancy and double vacancies. They thought that the defect formation energies are greatly dependent on local chemical bonding. Sang et al. ${ }^{31}$ reported the atomic defects in monolayer $\mathrm{Ti}_{3} \mathrm{C}_{2} \mathrm{~T}_{x}$ MXene. They reported that the formation energy of Ti-vacancy on $\mathrm{Ti}_{3} \mathrm{C}_{2} \mathrm{O}_{x}$ $(7.74 \mathrm{eV})$, and the defects can't strongly influence the metallic conductivity, but can influence the surface morphology and termination groups. To the best of our knowledge, limited researches report the impact of different vacancy defect on the properties of $\mathrm{Ti}_{2} \mathrm{CO}_{2}$ monolayer. 


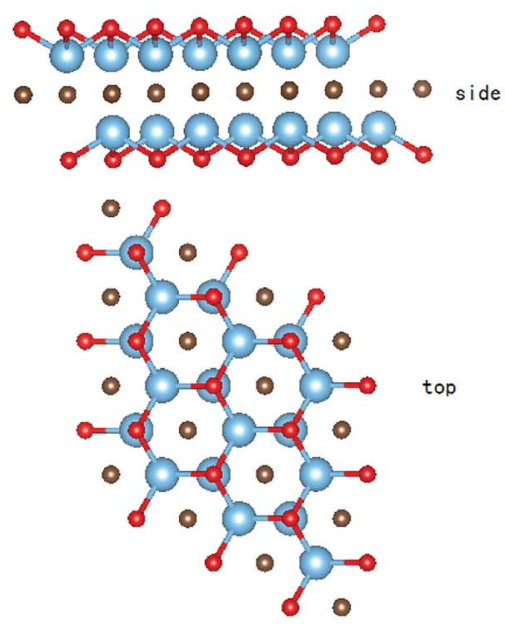

(a)
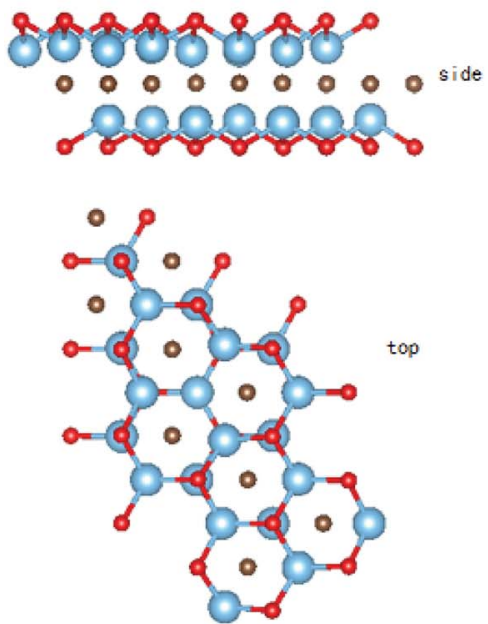

(c)

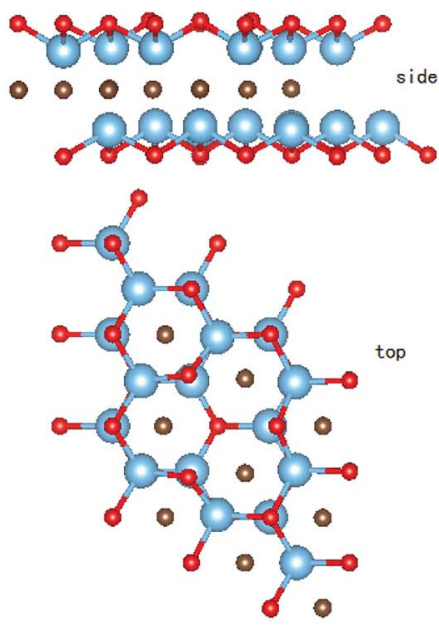

(b)
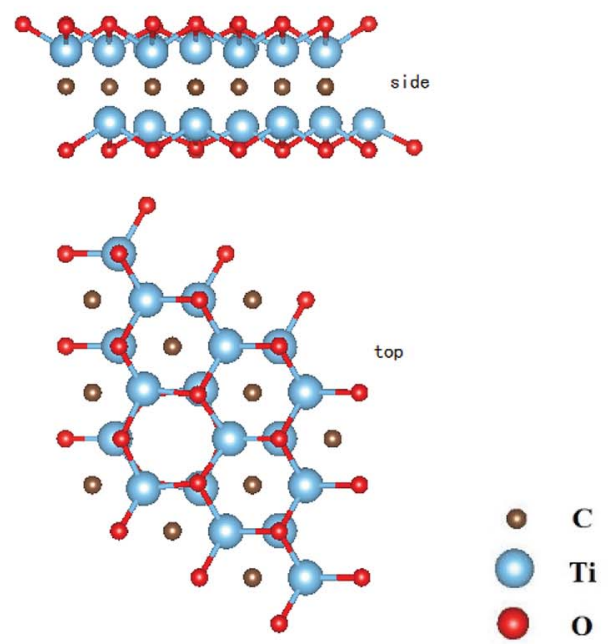

(d)

Fig. 1 The atomic structures of pristine $\mathrm{Ti}_{2} \mathrm{CO}_{2}(\mathrm{a}), \mathrm{Ti}_{2} \mathrm{CO}_{2}-\mathrm{V}_{\mathrm{Ti}}(\mathrm{b}), \mathrm{Ti}_{2} \mathrm{CO}_{2}-\mathrm{V}_{\mathrm{O}}$ (c), and $\mathrm{Ti}_{2} \mathrm{CO}_{2}-\mathrm{V}_{\mathrm{C}}$ (d) from top and side view.

Work function (WF) is an important parameter for electrode materials. A material with higher WF can be as an anode, and a material with low WF can be treated as a cathode. Research ${ }^{32}$ indicates that the materials with higher work function can reduce the Schottky barrier, which can cause increased contact resistances and limit the performance of devices. Therefore, the modulation of WF is important to improve the device performance. Up to now, the report on the modulation of WF of $\mathrm{Ti}_{2} \mathrm{CO}_{2}$ monolayer is unavailable.

Here, we investigated the effect of carbon vacancy $\left(\mathrm{V}_{\mathrm{C}}\right)$, Ti vacancy $\left(\mathrm{V}_{\mathrm{Ti}}\right)$, and oxygen vacancy $\left(\mathrm{V}_{\mathrm{O}}\right)$ on structure, electronic properties, and work function of $\mathrm{Ti}_{2} \mathrm{CO}_{2}$ monolayer. The comparisons of related properties between pristine and vacancy $\mathrm{Ti}_{2} \mathrm{CO}_{2}$ monolayer and the modulation of vacancy defect on WF are performed in our study, which are not discussed in other people's works. ${ }^{29-31}$ Our investigation will provide an alternative method to engineer the physical and chemical properties of MXenes.

\section{Computational details}

All density functional theory (DFT) calculations are carried out using the Dmol $^{3}$ code $^{33}$ The Perdew-Burke-Ernzerhof (PBE) functional ${ }^{34}$ generalized gradient approximation $(\mathrm{GGA})^{35}$ is used. The used basis set is double numerical plus polarization (DNP), which corresponds to a double- $\zeta$ quality basis set with ptype polarization functions added to hydrogen, and d-type polarization functions added to heavier atoms. DNP basis set is comparable with the Gaussian $6-31 \mathrm{G}(\mathrm{d}, \mathrm{p})$ basis set and exhibits a better accuracy. ${ }^{36} \mathrm{~A} 3 \times 3 \times 1 \mathrm{Ti}_{2} \mathrm{CO}_{2}$ supercell is constructed with one carbon, titanium, or oxygen removal to highlight the influence of $\mathrm{V}_{\mathrm{C}}, \mathrm{V}_{\mathrm{Ti}}$, and $\mathrm{V}_{\mathrm{O}}$, respectively. The three models of $\mathrm{Ti}_{2} \mathrm{CO}_{2}-\mathrm{V}_{\mathrm{C}}, \mathrm{Ti}_{2} \mathrm{CO}_{2}-\mathrm{V}_{\mathrm{Ti}}$, and $\mathrm{Ti}_{2} \mathrm{CO}_{2}-\mathrm{V}_{\mathrm{O}}$ monolayers are presented in Fig. 1. In order to have a comparison, the structure of pristine $\mathrm{Ti}_{2} \mathrm{CO}_{2}$ monolayer (PTM) is also presented in Fig. 1 .

In order to simulate the isolated monolayer, a large vacuum space of $25 \AA$ was set in the direction normal to MXene layers to 
avoid any unnecessary interaction between the MXene layers. In our calculation, the Brillouin zone (BZ) integration was sampled by using a $5 \times 5 \times 1 \mathrm{k}$-mesh according to Monkhorst-Pack method. ${ }^{37}$ The convergence in energy, force and displacement were $1 \times 10^{-6} \mathrm{Ha}, 0.001 \mathrm{Ha} \AA^{-1}$, and $0.005 \AA$, respectively. A denser $9 \times 9 \times 1$ mesh is used to calculate the electronic density of states (DOS).

\section{Results and discussion}

\subsection{The structure of pristine and defect- $\mathrm{Ti}_{2} \mathrm{CO}_{2}$ monolayer}

In order to determine what defects are likely to form, the vacancy formation energies $E_{\text {form }}$ for $\mathrm{Ti}, \mathrm{C}$, or O defect are obtained by the following equation:

$$
E_{\text {form }}=E_{\text {vac }}+U_{\text {atom }}-E_{\text {pristine }}
$$

where $E_{\text {form }}$ is the vacancy formation energy, $E_{\mathrm{vac}}$ is the total energy of $\mathrm{Ti}_{2} \mathrm{CO}_{2}$ monolayer with mono-vacancy, $U_{\text {atom }}$ is the total energy of an isolated atom, $E_{\text {pristine }}$ is the total energy of pristine $\mathrm{Ti}_{2} \mathrm{CO}_{2}$ monolayer (PTM). The calculated O-vacancy formation energy is $6.59 \mathrm{eV}$, lower than Ti-vacancy formation energy $(9.67 \mathrm{eV})$, and higher than C-vacancy formation energy $(5.31 \mathrm{eV})$. So C-vacancy is energetically more favorable than Tivacancy and O-vacancy, which is consistent with the conclusion of other researches. ${ }^{29,30,38}$ Ti-vacancy and O-vacancy are not easy to occur when compared with C-vacancy, but they can be induced in non-equilibrium processes such as e-beam lithography, ${ }^{39}$ which is used to decorate the vacancy defects in the $\mathrm{MoS}_{2}$ monolayer. ${ }^{40}$ Ti-vacancy deformation is more energy consuming when compared with O-vacancy and C-vacancy, which is consistent with the other researchers' results. ${ }^{29,31}$ Sang et $a{ }^{31}$ reported the formation energy of Ti-vacancy on
$\mathrm{Ti}_{3} \mathrm{C}_{2} \mathrm{O}_{x}(7.74 \mathrm{eV})$, which indicates that Ti-vacancy is more difficult to occur on $\mathrm{Ti}_{2} \mathrm{CO}_{2}$ monolayer $(9.67 \mathrm{eV})$ than $\mathrm{Ti}_{3} \mathrm{C}_{2} \mathrm{O}_{x}$.

The calculated crystal parameter of PTM is $9.0483 \AA$, while the crystal parameters of $\mathrm{Ti}_{2} \mathrm{CO}_{2}$ monolayers with $\mathrm{Ti}, \mathrm{C}$, or O defect are 9.0737, 9.0719, and 9.0636 А, respectively. So the crystal parameters of $\mathrm{Ti}_{2} \mathrm{CO}_{2}-\mathrm{V}_{\mathrm{C}}, \mathrm{Ti}_{2} \mathrm{CO}_{2}-\mathrm{V}_{\mathrm{Ti}}$, and $\mathrm{Ti}_{2} \mathrm{CO}_{2}-\mathrm{V}_{\mathrm{O}}$ monolayers change slightly when compared with that of PTM. The volume of PTM is $1665.59 \AA^{3}$. Compared with the volume of PTM, the volume of $\mathrm{Ti}_{2} \mathrm{CO}_{2}-\mathrm{V}_{\mathrm{C}}$ monolayer increases $1.99 \%$. The creation of $\mathrm{C}$ vacancy makes the $\mathrm{Ti}$ atoms near $\mathrm{C}$ vacancy away from the vacancy by the remaining strengthened pd bonds, which results in the volume increase of $\mathrm{Ti}_{2} \mathrm{CO}_{2}-\mathrm{V}_{\mathrm{C}}$. Compared with the volume of PTM, the volume of $\mathrm{Ti}_{2} \mathrm{CO}_{2}-\mathrm{V}_{\mathrm{Ti}}$ increases by $2.01 \%$. The reason is that the creation of Ti vacancy makes the formation of unsaturated electrons on nearest $\mathrm{C} / \mathrm{O}$ atoms, which result in the stronger interactions between $\mathrm{C} / \mathrm{O}$ atoms and their nearest $\mathrm{Ti}$ atoms. The volume of $\mathrm{Ti}_{2} \mathrm{CO}_{2}-\mathrm{V}_{\mathrm{O}}$ increases by $1.90 \%$ when compared to that of PTM. The creation of $\mathrm{O}$ vacancy on the surface of $\mathrm{Ti}_{2} \mathrm{CO}_{2}$ monolayer makes the charge redistribution, and results in the formation of the stronger $\mathrm{Ti}-\mathrm{O}$ and $\mathrm{Ti}-\mathrm{C}$ bonds near $\mathrm{O}$ vacancy.

\subsection{The electronic properties of pristine and defect- $\mathrm{Ti}_{2} \mathrm{CO}_{2}$ monolayers}

Fig. 2 presents the structures of pristine and defect $\mathrm{Ti}_{2} \mathrm{CO}_{2}$ monolayer along the symmetry directions $\Gamma-\mathbf{M}-\mathrm{K}-\Gamma$. The valence band maximum (VBM) and conduction band minimum (CBM) are labelled in Fig. 2. PTM is an $\mathrm{M}-\Gamma$ indirect semiconductor with the band gap of $0.27 \mathrm{eV}$, which is close to the results of Xie et al. $(0.24 \mathrm{eV} \text { by } \mathrm{PBE})^{41}$ and $\mathrm{Zha}$ et al. $(0.261 \mathrm{eV}$ by $\mathrm{PBE}){ }^{42}$ The introduction of vacancy defect results in the transition from semiconductor to metal.
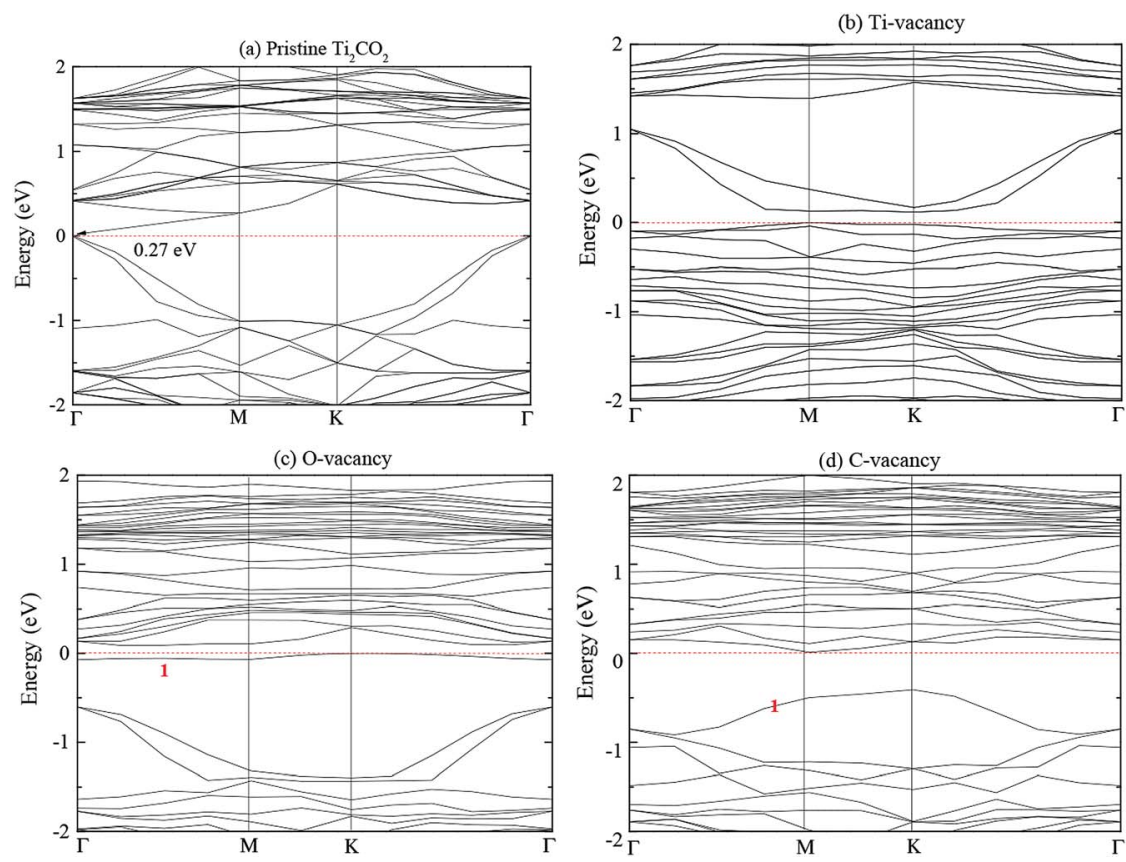

Fig. 2 The band structure of pristine and vacancy defect $\mathrm{Ti}_{2} \mathrm{CO}_{2}$ monolayer. 


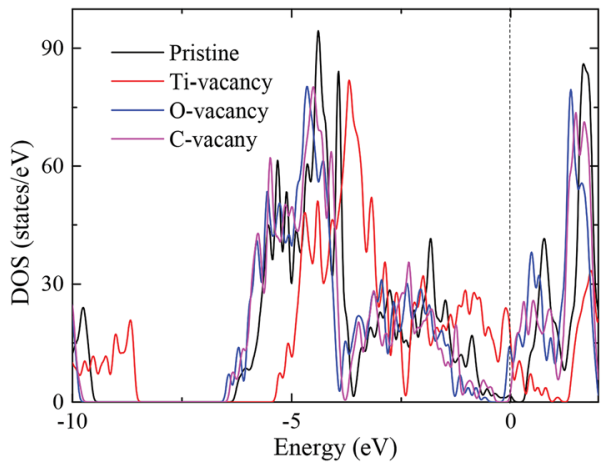

Fig. 3 The total density of states of pristine and vacancy defect $\mathrm{Ti}_{2} \mathrm{CO}_{2}$ monolayer.

From Fig. 2(b), the introduction of Ti-vacancy makes the Fermi energy level shift downward compared with that of PTM, and the valence band passes through the Fermi level, which results in the metallic character of $\mathrm{Ti}_{2} \mathrm{CO}_{2}-\mathrm{V}_{\mathrm{Ti}}$. Ti defect level lies in the valence band region of PTM. From Fig. 2(c), the introduction of $\mathrm{O}$ vacancy defect makes the Fermi energy level shift upward. The defect energy level (band 1 in Fig. 2(c)) appears because of the removal of one oxygen atom, which passes through the Fermi energy level and results in the metallization of $\mathrm{Ti}_{2} \mathrm{CO}_{2}-\mathrm{V}_{\mathrm{O}}$. This indicates that the $\mathrm{O}$ vacancy has greater effect on the photocatalyst properties of $\mathrm{Ti}_{2} \mathrm{CO}_{2}$ monolayer. In addition, it is noted that the defect energy level fluctuates slightly and changes gently, which indicates that the electrons in this energy level have larger effective mass, stronger localization and electron binding. From Fig. 2(d), the introduction of

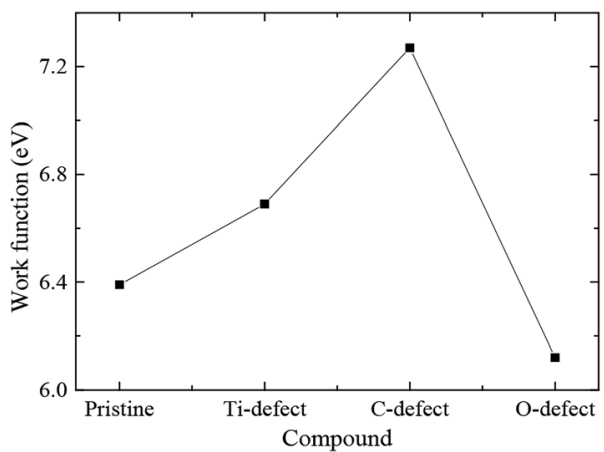

Fig. 5 The work function of pristine and vacancy defect $\mathrm{Ti}_{2} \mathrm{CO}_{2}$ monolayer.

C vacancy makes the Fermi level shift upward compared with that of PTM. The defect energy level (band 1 in Fig. 2(d)) is introduced below the Fermi level. So the vacancy defect can effectively engineer the band structure of $\mathrm{Ti}_{2} \mathrm{CO}_{2}$ monolayer.

Fig. 3 presents the total density of state (DOS) of pristine and vacancy defect $\mathrm{Ti}_{2} \mathrm{CO}_{2}$ monolayer. It is noted that the introduction of vacancy defect imposes the significant impact on the electronic structure of $\mathrm{Ti}_{2} \mathrm{CO}_{2}$ monolayer. The improved electronic conductivities of $\mathrm{Ti}_{2} \mathrm{CO}_{2}-\mathrm{V}_{\mathrm{Ti}}, \mathrm{Ti}_{2} \mathrm{CO}_{2}-\mathrm{V}_{\mathrm{O}}$, and $\mathrm{Ti}_{2} \mathrm{CO}_{2}-\mathrm{V}_{\mathrm{C}}$ monolayers are observed due to the significantly increased DOS at the Fermi level $\left(E_{\mathrm{F}}\right)$. So the introduction of vacancy defect can improve the electronic conductivities of functionalized MXenes.

Fig. 4 presents the partial density of state (PDOS) of Ti, O, and $\mathrm{C}$ atoms of vacancy defect $\mathrm{Ti}_{2} \mathrm{CO}_{2}$ monolayer in order to illustrate the origin of electronic conductivity. The PDOS of PTM
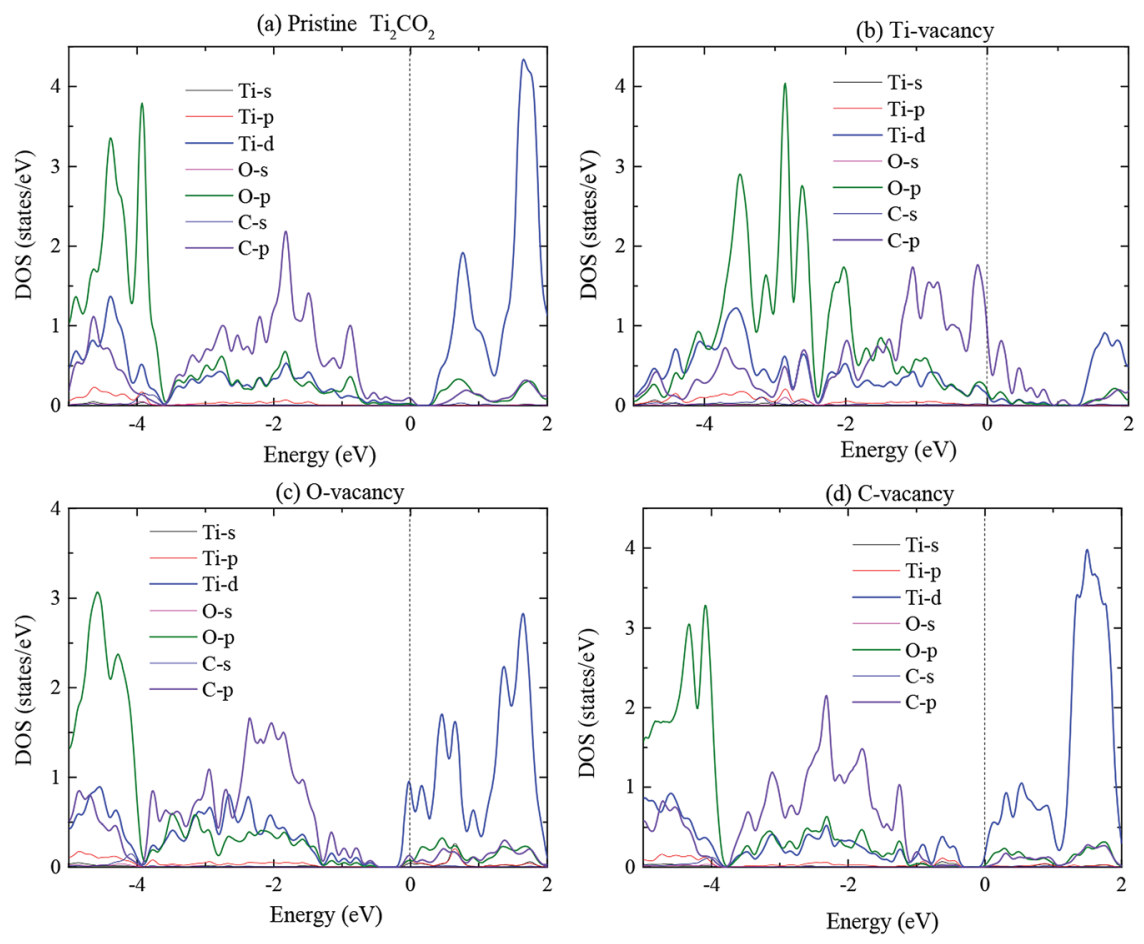

Fig. 4 The partial density of states of pristine and vacancy defect $\mathrm{Ti}_{2} \mathrm{CO}_{2}$ monolayer. 


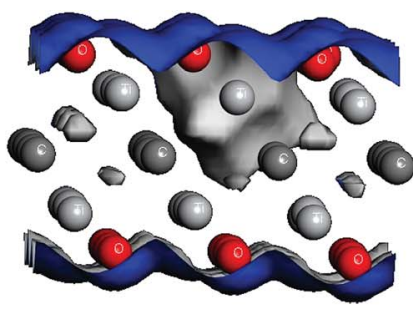

(a) $\mathrm{Ti}_{2} \mathrm{CO}_{2}-\mathrm{V}_{\mathrm{Ti}}$

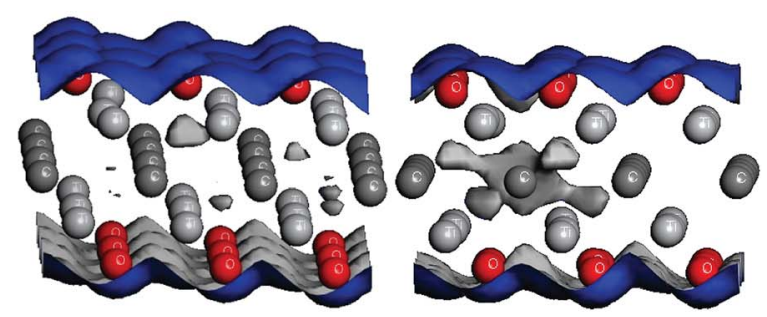

(b) $\mathrm{Ti}_{2} \mathrm{CO}_{2}-\mathrm{VO}_{\mathrm{O}}$

(c) $\mathrm{Ti}_{2} \mathrm{CO}_{2}-\mathrm{Vc}$

Fig. 6 The electrostatic potentials of $\mathrm{Ti}_{2} \mathrm{CO}_{2}-\mathrm{V}_{\mathrm{T}}, \mathrm{Ti}_{2} \mathrm{CO}_{2}-\mathrm{V}_{\mathrm{O}}$, and $\mathrm{Ti}_{2} \mathrm{CO}_{2}-\mathrm{V}_{\mathrm{C}}$ monolayers.

is also plotted in order to have a comparison. For PTM, the valence band is mainly from the contribution of Ti-d, C-p and Op states, while the conduction band is mainly from the contribution of Ti-d states. Similar to PTM, Ti-d, O-p, and C-p states provide the mainly contribution of valence band for $\mathrm{Ti}_{2} \mathrm{CO}_{2}-\mathrm{V}_{\mathrm{Ti}}$ monolayer, while C-p states mainly contribute to the conduction band. For $\mathrm{Ti}_{2} \mathrm{CO}_{2}-\mathrm{V}_{\mathrm{O}}$ and $\mathrm{Ti}_{2} \mathrm{CO}_{2}-\mathrm{V}_{\mathrm{C}}$ monolayers, Ti-d, O-p and C-p states provide the mainly contribution to valence band and conduction band. Combined Fig. 2 and 4 , for $\mathrm{Ti}_{2} \mathrm{CO}_{2}-$ $\mathrm{V}_{\mathrm{Ti}}$ monolayer, the band at $\Gamma$ point is mainly localized on C-p state, the introduction of Ti vacancy results in the unsaturated $\mathrm{C}$ and $\mathrm{O}$ atoms. For $\mathrm{Ti}_{2} \mathrm{CO}_{2}-\mathrm{V}_{\mathrm{O}}$ monolayer, the introduction of $\mathrm{O}$ vacancy results in three unsaturated Ti-3d states, which have the main contribution to the band at $\Gamma$ point. The introduction of $\mathrm{C}$ vacancy results in the six unsaturated $\mathrm{Ti}$ atoms for $\mathrm{Ti}_{2} \mathrm{CO}_{2^{-}}$ $\mathrm{V}_{\mathrm{C}}$ monolayer, so Ti-d state have the main contribution to the band at $\Gamma$ point and VBM from Fig. $4(\mathrm{~d})$.

It is noted that the introduction of $\mathrm{C}$ and $\mathrm{O}$ vacancy makes Ti-d state split into several peaks in the energy range of 0 to $2 \mathrm{eV}$ because of the structural modification. While the introduction of Ti vacancy makes Ti-d state weaker and C-p state stronger. Combined with Fig. 3 and 4 , the valley of the total DOS at $-3.5 \mathrm{eV}$ in Fig. 3 is mainly from Ti-d state for $\mathrm{Ti}_{2} \mathrm{CO}_{2}-\mathrm{V}_{\mathrm{Ti}}$ monolayer, Ti-d, O-p and C-p states for $\mathrm{Ti}_{2} \mathrm{CO}_{2}-\mathrm{V}_{\mathrm{O}}$ and $\mathrm{Ti}_{2} \mathrm{CO}_{2}{ }^{-}$ $\mathrm{V}_{\mathrm{C}}$ monolayers. In the energy range of -3 to $0 \mathrm{eV}$, there exist strong interactions between Ti-d and C-p states, Ti-d and O-p states for all studied $\mathrm{Ti}_{2} \mathrm{CO}_{2}$ monolayers.

\subsection{The analysis of work function and atomic charge}

Work function (WF) is an important physical parameter of materials and plays the significant role in the light emitting diodes and the field effect transistors. The work function of pristine $\mathrm{Ti}_{2} \mathrm{CO}_{2}$ monolayer is $6.39 \mathrm{eV}$, while the work functions of $\mathrm{Ti}_{2} \mathrm{CO}_{2}-\mathrm{V}_{\mathrm{C}}, \mathrm{Ti}_{2} \mathrm{CO}_{2}-\mathrm{V}_{\mathrm{Ti}}$, and $\mathrm{Ti}_{2} \mathrm{CO}_{2}-\mathrm{V}_{\mathrm{O}}$ monolayers are 7.27, 6.69 , and $6.12 \mathrm{eV}$, respectively. This indicates that the work function can be effectively engineered by vacancy defect. According to the report of Ma et al., ${ }^{32} \mathrm{Ti}_{2} \mathrm{CO}_{2}-\mathrm{V}_{\mathrm{C}}$ and $\mathrm{Ti}_{2} \mathrm{CO}_{2}-\mathrm{V}_{\mathrm{Ti}}$ monolayers with higher WFs can reduce the Schottky barrier and decrease the field emission performance, while $\mathrm{Ti}_{2} \mathrm{CO}_{2}-\mathrm{V}_{\mathrm{O}}$ monolayer with lower $\mathrm{WF}$ can improve the field emission performance. In the other hand, $\mathrm{Ti}_{2} \mathrm{CO}_{2}-\mathrm{V}_{\mathrm{C}}$ and $\mathrm{Ti}_{2} \mathrm{CO}_{2}-\mathrm{V}_{\mathrm{Ti}}$ monolayers can be considered as anode because of the higher WFs, while $\mathrm{Ti}_{2} \mathrm{CO}_{2}-\mathrm{V}_{\mathrm{O}}$ monolayer can be considered as cathode due to the lower WF (Fig. 5).
The analysis of Mulliken charge is performed in order to further investigate the effect of vacancy defect on the charge distribution. Fig. 6 presents the electrostatic potential of $\mathrm{Ti}_{2} \mathrm{CO}_{2}-\mathrm{V}_{\mathrm{Ti}}, \mathrm{Ti}_{2} \mathrm{CO}_{2}-\mathrm{V}_{\mathrm{O}}$, and $\mathrm{Ti}_{2} \mathrm{CO}_{2}-\mathrm{V}_{\mathrm{C}}$ monolayers. For PTM, the charge of Ti atom in supercell is $1.202 e^{-}$, while the charges of the adjacent $\mathrm{C}$ and $\mathrm{O}$ atoms are -0.980 and $-0.712 e^{-}$, respectively. For $\mathrm{Ti}_{2} \mathrm{CO}_{2}-\mathrm{V}_{\mathrm{Ti}}$ monolayer, the removal of Ti atom results in the charge localization on the defect site, adjacent unsaturated $\mathrm{O}$ and $\mathrm{C}$ atoms. The negative charge accumulation is exhibited around Ti vacancy defect. The charge aggregation is exhibited around $\mathrm{O}$ atoms, while the loss of negative charge is exhibited around $\mathrm{C}$ atoms. The charges of the adjacent $\mathrm{C}$ and $\mathrm{O}$ atoms are -0.704 and $-0.584 e^{-}$, respectively. For $\mathrm{Ti}_{2} \mathrm{CO}_{2}-\mathrm{V}_{\mathrm{O}}$ monolayer, the positive charge accumulation is exhibited around $\mathrm{O}$ vacancy defect. The charge of the adjacent Ti atom is $1.187 e^{-}$, while the charge of the adjacent $\mathrm{C}$ atom has little change because of the longer distance from $\mathrm{O}$ vacancy. From Fig. 6(c), there is a clear charge accumulation around $\mathrm{C}$ vacancy defect for $\mathrm{Ti}_{2} \mathrm{CO}_{2}{ }^{-}$ $\mathrm{V}_{\mathrm{C}}$ monolayer. The charge of the adjacent Ti atom is $1.189 e^{-}$, while the charge of adjacent $\mathrm{O}$ atom increases and is $-0.708 \mathrm{e}^{-}$. The introduction of $\mathrm{C}$ vacancy weakens the adjacent Ti-O bonds.

\section{Conclusion}

In this paper, the structure, electronic properties of pristine and vacancy defect $\mathrm{Ti}_{2} \mathrm{CO}_{2}$ monolayer have been investigated by the first principles calculation. The analysis of formation energies indicates that C-vacancy is energetically more favorable than Tivacancy and O-vacancy. PTM is a semiconductor. The introduction of vacancy defect results in the metallic character of $\mathrm{Ti}_{2} \mathrm{CO}_{2}$ monolayer and improves the electronic conductivity of $\mathrm{Ti}_{2} \mathrm{CO}_{2}$ monolayer. The work function can be effectively engineered by vacancy defect. $O$ vacancy defect can improve the field emission performance, while $\mathrm{Ti}$ or $\mathrm{C}$ vacancy defect can decrease the field emission performance for $\mathrm{Ti}_{2} \mathrm{CO}_{2}$ monolayer. The analysis of Mulliken charge is further performed.

\section{Conflicts of interest}

There are no conflicts to declare.

\section{Acknowledgements}

We gratefully thank the National Natural Science Foundation of China (Grant U1304111), and the Program for Science \& 
Technology Innovation Talents in the Universities of Henan Province (No. 14HASTIT039) and the Innovation Team of Henan University of Science and Technology (2015XTD001) for their support of this work.

\section{References}

1 K. S. Novoselov, A. K. Geim, S. V. Morozov, D. Jiang, M. I. Katsnelson, I. V. Grigorieva, S. V. Dubonos and A. A. Firsov, Nature, 2005, 438, 197.

2 K. S. Novoselov, D. Jiang, F. Schedin, T. J. Booth, V. V. Khotkevich, S. V. Morozov and A. K. Geim, Proc. Natl. Acad. Sci. U. S. A., 2005, 102, 10451.

3 M. Naguib, V. N. Mochalin, M. W. Barsoum and Y. Gogotsi, Adv. Mater., 2014, 26, 992.

4 Y. Gogotsi, Nat. Mater., 2015, 14, 1079.

5 M. Naguib and Y. Gogotsi, Acc. Chem. Res., 2015, 48, 128.

6 M. Ghidiu, M. R. Lukatskaya, M. Q. Zhao, Y. Gogotsi and M. W. Barsoum, Nature, 2014, 516, 78.

7 M. Hu, Z. Li, G. Li, T. Hu, C. Zhang and X. Wang, Adv. Mater. Technol., 2017, 2, 1700143.

8 Q. M. Peng, J. X. Guo, Q. R. Zhang, J. Y. Xiang, B. Z. Liu, A. G. Zhou, R. P. Liu and Y. J. Tian, J. Am. Chem. Soc., 2014, 136, 4113.

9 X. Zhang, Z. Zhang, J. Li, X. Zhao, D. Wu and Z. Zhou, J. Mater. Chem. A, 2017, 5, 12899.

10 M. Naguib, V. N. Mochalin, M. W. Barsoum and Y. Gototsi, Adv. Mater., 2014, 26, 992.

11 D. Magne, V. Mauchamp, S. Celerier, P. Chartier and T. Cabioch, Phys. Rev. B: Condens. Matter Mater. Phys, 2015, 91, 201409.

12 Y. Xie, M. Naguib, V. N. Mochalin, M. W. Barsoum, Y. Gogotsi, X. Yu, K.-W. Nam, X.-Q. Yang, A. I. Kolesnikov and P. R. C. Kent, J. Am. Chem. Soc., 2014, 136, 6385.

13 C. Eames and M. S. Islam, J. Am. Chem. Soc., 2014, 136, 16270.

14 Y. Xie, Y. Dall'Agnese, M. Naguib, Y. Gogotsi, M. W. Barsoum, H. L. Zhuang and P. R. C. Kent, ACS Nano, 2014, 8, 9606.

15 R. Bourrellier, S. Meuret, A. Tararan, O. Stéphan, M. Kociak and L. H. G. Tizei, Nano Lett., 2016, 16, 4317.

16 D. Wong, J. Velasco, L. Ju, J. Lee, S. Kahn, H.-Z. Tsai, C. Germany, T. Taniguchi, K. Watanabe, A. Zettl, F. Wang and M. F. Crommie, Nanotechnol, 2015, 10, 949.

17 T. T. Tran, K. Bray, M. J. Ford, M. Toth and I. Aharonovich, Nat. Nanotechnol., 2015, 11, 37.

18 W. M. Parkin, A. Balan, L. Liang, P. M. Das, M. Lamparski, C. H. Naylor, J. A. RodriguezManzo, A. T. Johnson, V. Meunier and M. Drndic, ACS Nano, 2016, 10, 4134.

19 H. Zhang, T. Hu, X. H. Wang, Z. J. Li, M. M. Hu, E. D. Wu and Y. C. Zhou, Sci. Rep., 2015, 5, 14192.
20 A. I. Gusev, Disorder and Order in Strongly Nonstoichiometric Compounds: Transition Metal Carbides, Nitrides and Oxides, Springer, New York, 2001.

21 J. Nguyen, N. Glandut, C. D. Jaoul and P. Lefort, Langmuir, 2013, 29, 12036.

22 X. X. Yu, G. B. Thompson and C. R. Weinberger, J. Eur. Ceram. Soc., 2015, 35, 95.

23 H. Wang, H. Han, G. Yin, C.-Y. Wang, Y.-Y. Hou, J. Tang, J.-X. Dai, C.-L. Ren, W. Zhang and P. Huai, Materials, 2017, 10(2), 103.

24 H. Han, D. Wickramaratne, Q. Huang, J. X. Dai, T. W. Li, H. Wang, W. Zhang and P. Huai, RSC Adv., 2016, 6, 84262.

25 X.-F. Yu, Y.-C. Li, J.-B. Cheng, Z.-B. Liu, Q.-Z. Li, W.-Z. Li, X. Yang and B. Xiao, ACS Appl. Mater. Interfaces, 2015, 7, 13707.

26 X.-F. Yu, J.-B. Cheng, Z.-B. Liu, Q.-Z. Li, W.-Z. Li, X. Yang and B. Xiao, RSC Adv., 2015, 5, 30438.

27 X. Zhang, Z. Zhang, J. Li, X. Zhao, D. Wu and Z. Zhou, J. Mater. Chem. A, 2017, 5, 12899.

28 C. Wang, H. Han and Y. Guo, Comput. Mater. Sci., 2019, 159, 127.

29 T. Hu, J. Yang and X. Wang, Phys. Chem. Chem. Phys., 2017, 19, 31773.

30 A. Bandyopadhyay, D. Ghoshb and K. Swapan Pati, Phys. Chem. Chem. Phys., 2018, 20, 4012.

31 X. Sang, Y. Xie, M. W. Lin, M. Alhabeb, K. L. Van Aken, Y. Gogotsi, P. R. Kent and K. Xiao, ACS Nano, 2016, 10, 9193.

32 Y. Ma, C. Shen, A. Zhang, L. Chen, Y. Liu, J. Chen, Q. Liu, Z. Li, R. M. Amer, T. Nilges, N. Ahmad Abbas and C. Zhou, ACS Nano, 2017, 11, 7126.

33 B. Delley, J. Chem. Phys., 1990, 92, 508.

34 J. P. Perdew, K. Burke and M. Ernzerhof, Phys. Rev. Lett., 1996, 77, 3865.

35 P. E. Blöchl, Phys. Rev. B: Condens. Matter Mater. Phys., 1994, 50, 17953.

36 M. Wang, H. Liu, Z.-H. Huang and F. Kang, Chem. Eng. J., 2014, 256, 101.

37 H. J. Monkhorst and J. D. Pack, Phys. Rev. B: Solid State, 1976, 13, 5188.

38 H. Han, D. Wickramaratne, Q. Huang, J. X. Dai, T. W. Li, H. Wang, W. Zhang and P. Huai, RSC Adv., 2016, 6, 84262.

39 J. M. Gibson, Phys. Today, 1997, 50, 56.

40 H. P. Komsa, J. Kotakoski, S. Kurasch, O. Lehtinen, U. Kaiser and A. V. Krasheninnikov, Phys. Rev. Lett., 2012, 109, 035503.

41 Y. Xie and P. R. C. Kent, Phys. Rev. B: Condens. Matter Mater. Phys., 2013, 87, 235441.

42 X.-H. Zha, K. Luo, Q. Li, Q. Huang, J. He, X. Wen and S. Du, Europhys. Lett., 2015, 111, 26007. 